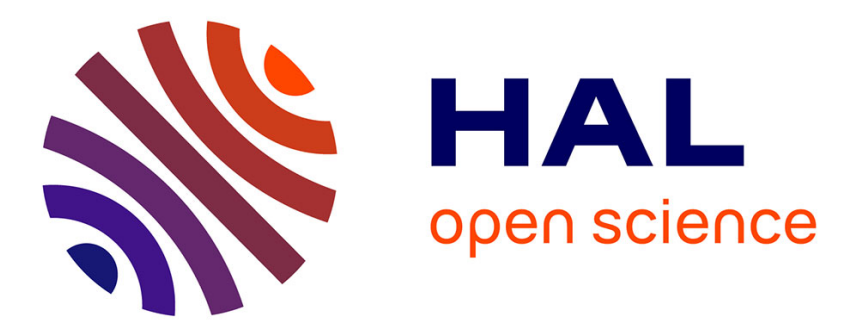

\title{
Luminescence of Ho-doped lithium niobate crystals highlighted by Raman Spectroscopy
}

Ninel Kokanyan, Edvard Kokanyan, Naira Babajanyan, T.H. Kauffmann, Marc D. Fontana

\section{> To cite this version:}

Ninel Kokanyan, Edvard Kokanyan, Naira Babajanyan, T.H. Kauffmann, Marc D. Fontana. Luminescence of Ho-doped lithium niobate crystals highlighted by Raman Spectroscopy. SPIE Optics + Photonics, SPIE, Aug 2018, San Diego, United States. 10.1117/12.2318550 hal-01863538

\section{HAL Id: hal-01863538 \\ https://hal.science/hal-01863538}

Submitted on 12 Sep 2018

HAL is a multi-disciplinary open access archive for the deposit and dissemination of scientific research documents, whether they are published or not. The documents may come from teaching and research institutions in France or abroad, or from public or private research centers.
L'archive ouverte pluridisciplinaire HAL, est destinée au dépôt et à la diffusion de documents scientifiques de niveau recherche, publiés ou non, émanant des établissements d'enseignement et de recherche français ou étrangers, des laboratoires publics ou privés. 


\section{Luminescence of Ho-doped lithium niobate crystals highlighted by Raman Spectroscopy}

N. Kokanyan, E. Kokanyan, N. Babajanyan, T. Kauffmann, M. D. Fontana

N. Kokanyan, E. Kokanyan, N. Babajanyan, T. Kauffmann, M. D. Fontana, "Luminescence of Ho-doped lithium niobate crystals highlighted by Raman Spectroscopy," Proc. SPIE 10750, Reflection, Scattering, and Diffraction from Surfaces VI, 107500K (4 September 2018); doi: 10.1117/12.2318550

Event: SPIE Optical Engineering + Applications, 2018, San Diego, California, United States 


\title{
Luminescence of Ho-doped lithium niobate crystals highlighted by Raman Spectroscopy
}

\author{
N. Kokanyan *a,b ${ }^{\text {E. E. Kokanyan }}{ }^{\mathrm{c}, \mathrm{d}}$, N. Babajanyan ${ }^{\mathrm{d}}$, T. Kauffmann ${ }^{\mathrm{a}, \mathrm{b}}$, M.D. Fontana ${ }^{\mathrm{a}, \mathrm{b}}$ \\ ${ }^{a}$ Laboratoire Matériaux Optiques, Photonique et Systèmes, CentraleSupélec, Université Paris- \\ Saclay, Metz, F-57070, France; ${ }^{b}$ Université de Lorraine, Laboratoire Matériaux Optiques, \\ Photonique et Systèmes, Metz, F-57070, France; ${ }^{c}$ Institute for Physical Researches, National \\ Academy of Sciences of Armenia, Ashtarak-2, Armenia; ${ }^{\mathrm{d}}$ Armenian State Pedagogical University, \\ Yerevan, Tigran Mets Ave., 17, Armenia.
}

\begin{abstract}
Raman measurements were carried out on $\mathrm{Ho}^{3+}$ doped Lithium Niobate crystals. When the excitation wavelength of $532 \mathrm{~nm}$ is used, in addition of expected Raman modes, forbidden bands are detected, while when exciting with $785 \mathrm{~nm}$, "classical" Raman spectrum was recorded with expected modes according to Raman selection rules. Additional lines are attributed to emission lines of Ho doped crystals. We detect, within a very good resolution, in the same Stokes spectrum, the transitions between the electronic states, and the vibrational states as well. We report on the analysis of these data as function of Ho-content, for different polarizations and wavelengths, of the incident laser beam.
\end{abstract}

Keywords: Lithium niobate, Raman spectroscopy, luminescence

\section{INTRODUCTION}

Lithium Niobate (LN) is one of the most used ferroelectrics having a wide number of applications such as phaseconjugation, holographic storage, frequency doubling, SAW sensors [1-3]. It is a versatile material, the properties of which can be changed according to the nature and concentration of doping [4-6]. Doping these crystals with rare earth impurity ions can be interesting for laser applications, and therefore characterization of emission spectra is required. Doping with holmium presents a special interest for up-conversion emission in green and red [7-9]. Moreover, recent works have shown that doping LN crystals by $\mathrm{Ho}^{3+}$ ions leads to the suppression of optical damage at $532 \mathrm{~nm}$ [8] and it can be used for optical cooling based on the anti-Stokes luminescence in the wavelength range around $2 \mu \mathrm{m}[10]$.

Raman spectroscopy is a powerful spectroscopic technique providing a possibility to obtain a number of information about physico-chemical as well as optical properties of a given material $[11,12]$. This technique was proved to be efficient to detect the influence of introduction of dopant ion in the lattice. Here it is used in order to investigate the emission states beside vibrational modes.

*ninel.kokanyan@centralesupelec.fr

Reflection, Scattering, and Diffraction from Surfaces VI, edited by Leonard M. Hanssen, Proc. of SPIE Vol. 10750, 107500K · (C) 2018 SPIE · CCC code: 0277-786X/18/\$18 - doi: 10.1117/12.2318550 


\section{EXPERIMENTAL PART AND ANALYSIS}

High purity materials in powder form from Johnson-Mattey $\left(\mathrm{Nb}_{2} \mathrm{O}_{5}\right)$ and Merck $\left(\mathrm{Li}_{2} \mathrm{CO}_{3}\right.$ and $\left.\mathrm{Ho}_{2} \mathrm{O}_{3}\right)$ were used to synthesize the initial material for the growth. $\mathrm{LN}$ powders doped with different concentrations $(0.1,1 \mathrm{~mol} \%)$ of $\mathrm{Ho}^{3+}$ ions were synthesized at $1000^{\circ} \mathrm{C}$ in two steps by solid reactions given below:

$$
\begin{gathered}
2 \mathrm{LiCO}_{3}+\mathrm{Nb}_{2} \mathrm{O}_{3} \rightarrow 2 \mathrm{LiNbO}_{3}+\mathrm{CO}_{2} \uparrow \\
2 \mathrm{LiNbO}_{3}+\mathrm{xHo}_{2} \mathrm{O}_{3} \rightarrow 2 \mathrm{Li}_{1-3 \mathrm{x}} \mathrm{Ho}_{\mathrm{x}} \mathrm{NbO}_{3}+3 \mathrm{xLi}_{2} \mathrm{O} \uparrow
\end{gathered}
$$

The obtained powders were investigated by the help of X-ray diffraction using Philips X'Pert diffractometer. The obtained results confirm existence of no any other phase than lithium niobate in above mentioned powders for all concentrations of impurity ions. In addition, the X-ray diffraction patterns allowed to determine the lattice parameters of the powders. In general, both a and c parameters of the Ho-doped powders under study increase, but if the behavior of the change of the $a$ parameter with the change of the concentration of the impurity ion can be attributed to a monotonous one, in the case of the c parameter it is not monotonous. Most probably it is due to the fact that site occupation of $\mathrm{Ho}^{3+}$ ions in the lattice of the $\mathrm{LN}$ is different depending of its concentration.

Congruent composition LN crystals doped with different of $\mathrm{Ho}^{3+}$ impurity ions were grown by the modified Czochralski method. The growth was realized in air using a setup with a high-frequency heating furnace and a platinum crucible having a size of $50 \times 3 \times 50 \mathrm{~mm}^{3}$. The crystals were pulled along the c-axis at a rate of $1 \mathrm{~mm} / \mathrm{h}$ and a rotation speed of about $20 \mathrm{rpm}$.

Among additions conditions of the growth process it should be noted, that during the mentioned process, a direct electric field (electrical current of about $12 \mathrm{~A} / \mathrm{m}^{2}$ ) was applied to the crystal-melt system in order to obtain single domain crystals directly during the growth process and a rather homogeneous distribution of impurity ions within all the grown crystal.

Raman spectra were carried out utilizing a confocal Raman microscope LabRAM HR Evolution (Horiba) with exciting lines of 532 and $785 \mathrm{~nm}$. The laser light was focused through a $50 \times$ objective (Olympus) at a distance above $1 \mathrm{~cm}$ from the sample. Raman system has a spectral resolution of $1 \mathrm{~cm}^{-1}$ using a grating with 1800 grooves per millimeter. In our series of measurements, we recorded backscattering Raman measurements in polarized configurations in order to obtain different Raman modes depending on their symmetry. The spectra were carried out in the configurations $\mathrm{Y}(\mathrm{ZZ}) \mathrm{Y}$ and $\mathrm{Y}(\mathrm{XZ}) \mathrm{Y}$ corresponding to $\mathrm{A} 1(\mathrm{TO})$ and $\mathrm{E}(\mathrm{TO})$ phonon modes respectively.

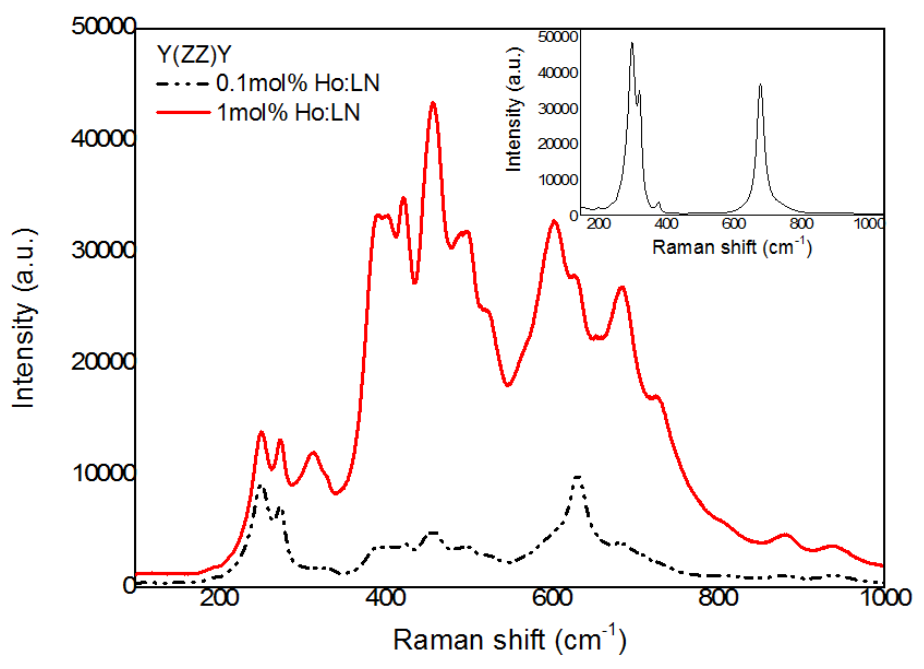

Fig. 1 - Spectra recorded with 532nm excitation wavelength on 0.1 and $1 \mathrm{~mol} \%$ Ho doped LN in Y(ZZ)Y configuration. The insert illustrates the spectrum of $1 \mathrm{~mol} \%$ Ho doped sample obtained with $785 \mathrm{~nm}$ laser. 
Figure 1 illustrates Raman spectra recorded on LN: 0.1 and $1 \mathrm{~mol} \%$ Ho with 532nm exciting laser line. According to Raman selection rules only $\mathrm{A}_{1}[\mathrm{TO}]$ modes are expected for $\mathrm{Y}(\mathrm{ZZ}) \mathrm{Y}$ configuration while we notice multiple additional forbidden lines in both spectra. Only difference is the higher intensity for $1 \mathrm{~mol} \%$ Ho doped LN sample comparing to $0.1 \mathrm{~mol} \%$ doped one. In contrast, when $785 \mathrm{~nm}$ is used solely $4 \mathrm{~A}_{1}[\mathrm{TO}]$ modes are detected. The same behavior is observed for $\mathrm{Y}(\mathrm{XZ}) \mathrm{Y}$ configuration where only $\mathrm{E}[\mathrm{TO}]$ modes are expected according to selection rules (figure 2).

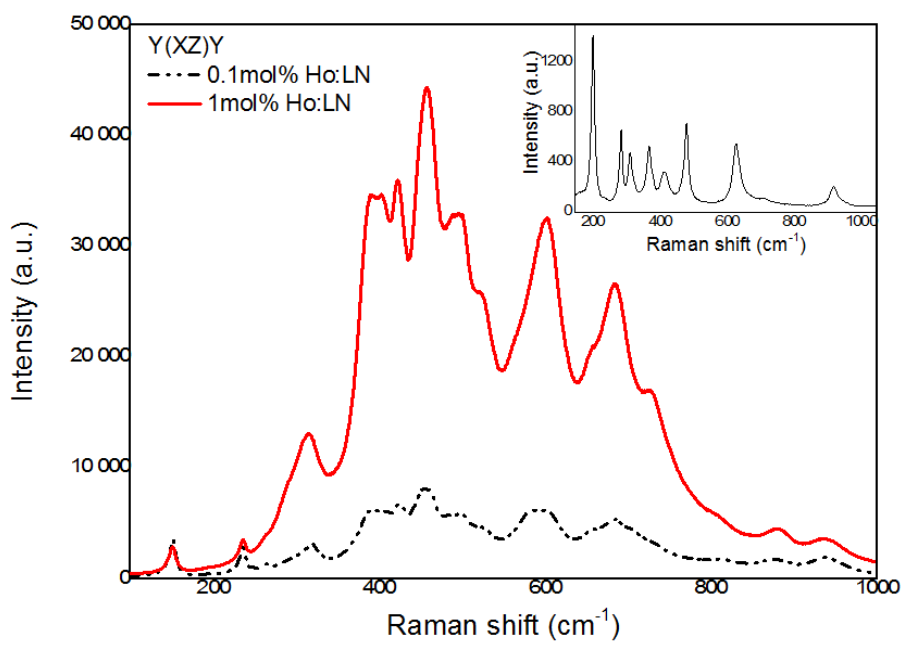

Fig. 2 - Spectra recorded with 532nm excitation wavelength on 0.1 and $1 \mathrm{~mol} \%$ Ho doped LN in Y(XZ)Y configuration. The insert illustrates the spectrum of $1 \mathrm{~mol} \%$ Ho doped sample obtained with $785 \mathrm{~nm}$ laser.

It is clear that these additional bands are not attributed to Raman modes and are related to the emission by $\mathrm{Ho}^{3+}$ ions in the crystal lattice. It should be pointed out that here the emission lines are as narrow as vibrational ones. That means that we detect within a very good resolution, Raman lines and emission lines simultaneously in the same Stokes scattering spectrum. In figure 3 we present spectra as a function of wavelength for both samples in both configurations. Our results are in rather good agreement with luminescence results reported in literature $[8,9]$

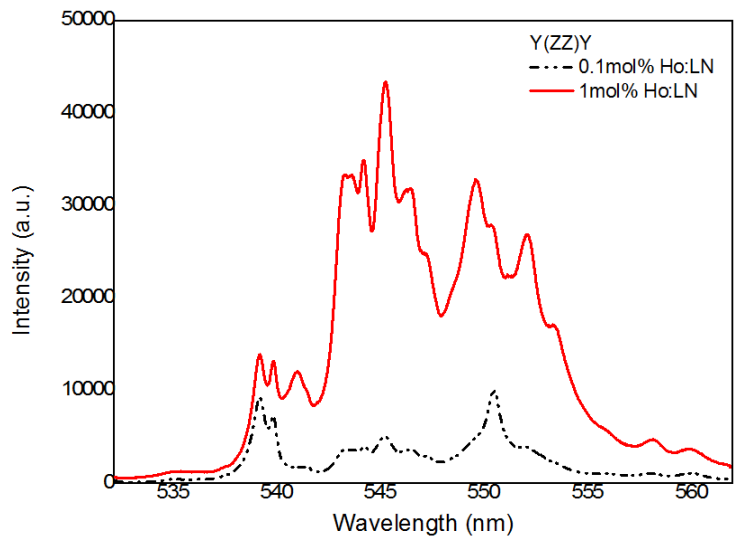

(a)

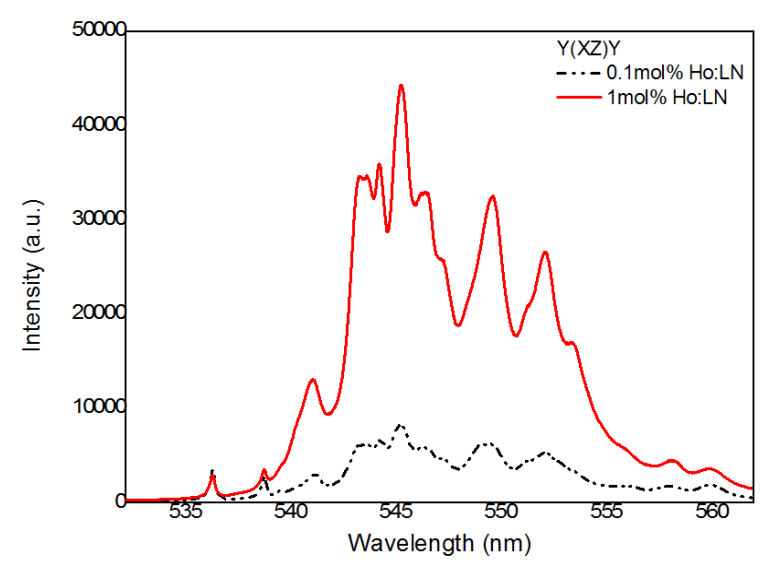

(b)

Fig. 3 - Spectra as a function of wavelength of 0.1 and 1\% mol Ho doped LN (a) Y(ZZ)Y configuration; (b) Y(XZ)Y configuration

Emission lines of Ho doped LN in the range of 535nm-560nm are assigned to ${ }^{5} \mathrm{~S}_{2}+{ }^{5} \mathrm{~F}_{4} \rightarrow{ }^{5} \mathrm{I}_{8}$ Stark transitions [8,9]. One can notice that emission spectra in two configurations are not totally identical (without taking into account Raman 
expected lines). This difference is related to $\pi$ and $\sigma$ emissions corresponding to $\mathrm{Y}(\mathrm{ZZ}) \mathrm{Y}$ and $\mathrm{Y}(\mathrm{XZ}) \mathrm{Y}$ configurations respectively. Our recent work [13] describes a methodology and data treatment procedure needed to separate Raman and emission lines in order to obtain purely the luminescence spectra.

\section{CONCLUSION}

Raman spectra of Ho doped LN were obtained with $532 \mathrm{~nm}$ and $785 \mathrm{~nm}$ excitation wavelengths and were found totally different from each other for both Ho concentrations $(0.1$ and $1 \mathrm{~mol} \%)$. Using $785 \mathrm{~nm}$ incident laser beam only Raman modes were detected in accordance with selection rules. In contrast, when using $532 \mathrm{~nm}$ laser in obtained spectra additional unexpected lines were detected. These spectra represent luminescence of Ho doped LN crystals superimposed on Raman modes. Obtained non-classical Raman spectra provide a possibility to acquire emission spectra with a rather good resolution. Our results are consonant with literature where emission spectra were obtained with optical absorption measurements.

\section{REFERENCES}

[1] Rauber, A. [Current Topics in Materials Science] E. Kaldis North-Holland, Amsterdam, 1, 481 (1978).

[2] Gunter, P., Huignard, J.P., [Photorefractive Materials and Their applications] Springer-Verlag, Heidelber, I, II, (1989).

[3] Aubert, T., Kokanyan, N., Alhousseini, A., Taguett, A., Bartoli, F., Streque, J., M'Jahed, H., Boulet, P., Elmazria, O., "First investigations on stoichiometric lithium niobate as piezoelectric substrate for high-temperature surface acoustic waves applications," Proc. 2017 IEEE Sensors, 576-578 (2017).

[4] Bazzan, M., Fontana, M.D., "Preface to Special Topic: Lithium Niobate Properties and Applications: Reviews of Emerging Trends". Appl. Phys. Rev. 2(4), 040501 (2015).

[5] Kokanyan, E.P., Razzari, L., Cristiani, I., Degiorgio, V., Gruber, J.B., "Reduced photorefraction in hafnium-doped single-domain and periodically poled lithium niobate crystals". Appl. Phys. Lett. 84, 1880 (2004).

[6] Kokanyan, N., Chapron, D., Kokanyan, E., Fontana, M.D., "Zr doping on lithium niobate crystals: Raman spectroscopy and chemometrics," J. of Applied Physics 121(9), 095103 (2017).

[7] Storm, M.E., Deyst, J.P., "Gain and energy storage in holmium YLF," IEEE Photonics Techn. letters, 3, 982 (1991).

[8] Barnes, E., O'Connell, N.H., Balli, N.R., Pokhrel, M., Movsesyan, A., Kokanyan, E., Sardar, D., "Suppression of optical damage at $532 \mathrm{~nm}$ in Holmium doped congruent lithium niobate," Optics Express, 22(21), 26222 (2014).

[9] Lorenzo, A., Bausa, L.E., Sanz Garcia, J.A., Garcia Solé, J., "Optical absorption intensities and fluorescence dynamics of $\mathrm{Ho}^{3+}$ ions in $\mathrm{LiNbO}_{3}$ " J. Phys.: Condens. Matter 8(31), 5781-5791 (1996).

[10] Demirkhanyan, G., Kokanyan, E., Demirkhanyan, H., Sardar, D., Aillerie, M., "Crystal LiNbO3:Ho3+: Material for optical cooling" J. of Contemporary Physics (Armenian Academy of Sciences) 51, 28-34 (2016).

[11] Bazzan, M., Kokanyan, N., Zaltron, A., Argiolas, N., Chapron, D., Fontana, M.D., "Raman frequency shift induced by photorefractive effect on Fe-doped lithium niobate," J. of Applied Physics, 114, 163506, (2013).

[12] Kokanyan, N., Chapron, D., Fontana, M.D., "Temperature dependence of Raman scattering and anharmonic properties in $\mathrm{LiNbO}_{3}$," Appl. Physics A, 117, 1147, (2014).

[13] Kauffmann, T., Kokanyan, N., Fontana, M.D., "Use of Stokes and anti-Stokes Raman scattering for new applications," J. of Raman Spectroscopy (2018) (to be published). 